\title{
Indoor air quality in a bus
}

\author{
A. Gajewski \\ Department of Heat Engineering, Faculty of Civil Engineering and \\ Environmental Engineering, Bialystok University of Technology, Poland
}

\begin{abstract}
This paper looks at indoor air qualities in a bus. Two experiments were done during an outbound and return journey with 24 passengers plus a driver. The focus of attention was carbon dioxide concentration. The permitted value 1000 ppm of $\mathrm{CO}_{2}$ was exceeded during the trip there and at the beginning of the return journey, the maximum measured concentration was $2400 \mathrm{ppm}$. The calculations of minimum share of fresh air to provide what was required by the standard conditions were undertaken. Too high $\mathrm{CO}_{2}$ concentration may contribute to dangerous situations on roads.
\end{abstract}

Keywords: carbon dioxide emissions, indoor air quality, bus, travel security.

\section{Introduction}

Bus transport is a relatively cheap and flexible kind of transport, because it gives possibility to transport the passengers from one door to another door. Therefore, this kind of people's travelling develops continuously. Hence, the indoor air quality (IAQ) should satisfy the proper standards: ASHRAE [4], European standard [2] or WHO [3]. However, indoor air quality (IAQ) in the buses has not been investigated so far. The most important parameter is carbon dioxide concentration which is not controlled by the proper system. Carbon dioxide is air component and it is not thought the gas is poisonous. However, if $\mathrm{CO}_{2}$ concentration rises up to $5 \%$ in air breathing its causes higher partial blood pressure, anxiety or makes breathing more difficult and more frequent. Higher $\mathrm{CO}_{2}$ concentration not to be ought to occur in the rooms, where people stay because health troubles are more serious (cf. Gładyszewska-Fiedoruk [1, pp. 166-171]). 


\section{Experiment}

Temperature, humidity and $\mathrm{CO}_{2}$ concentration were measured in a 31-person bus with 24 passengers and a driver on board. IAQ parameters were taken by testo 435-4 measuring instrument with IAQ probe that measures absolute pressure, temperature, relative humidity, and $\mathrm{CO}_{2}$ concentration simultaneously. Error uncertainties are plotted as the vertical line of Figures 1, 2, 3, and 4. Because, in the case of temperature the height of the line would be shorter than the marker size the uncertainty of temperature measurement is not plotted. The measured values at the beginning of the experiment were unstable due to adjustment procedure of the measuring instrument. Outside temperature changed from $11^{\circ} \mathrm{C}$ to $14^{\circ} \mathrm{C}$ during the journey there and it was at $17^{\circ} \mathrm{C}$ on the return one.

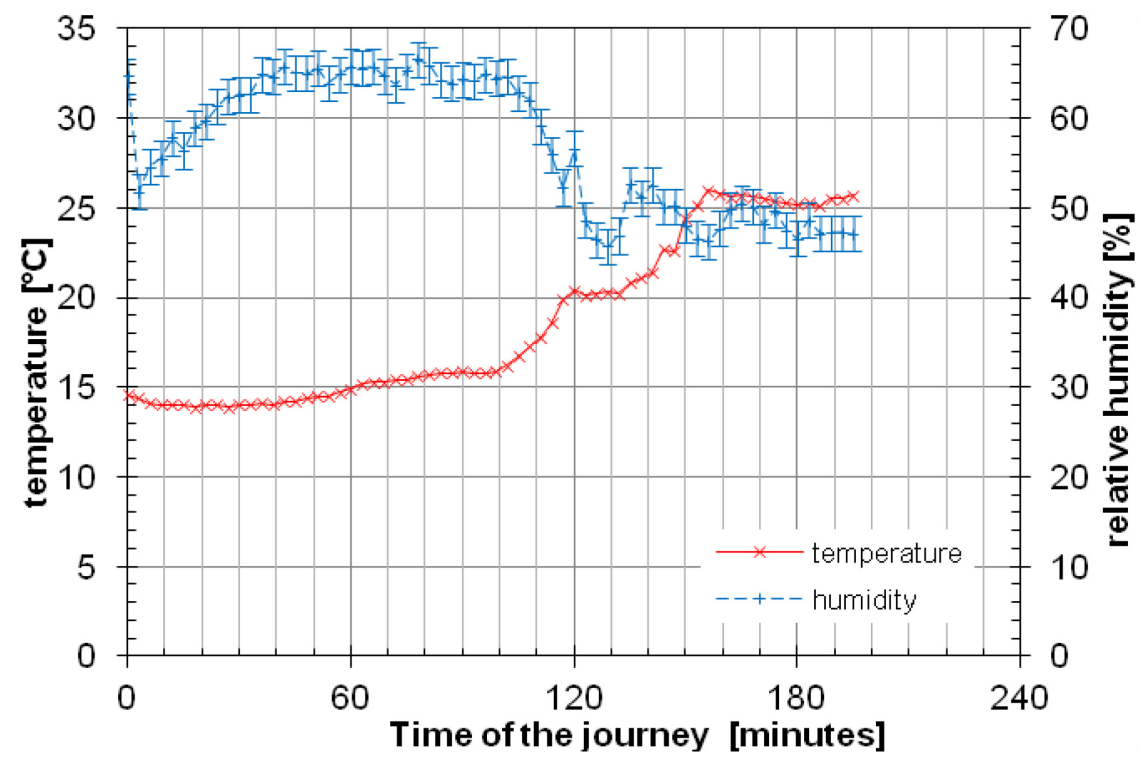

Figure 1: Temperature and relative humidity in the bus during the journey forth.

First, the probe was placed in the front part of the bus behind the driver on a seat, so the probe was below the passengers' heads. The temperature was almost constant for the first 100 minutes, while relative humidity rose for the first 40 minutes, then it oscillated about $65 \%$ for another hour (cf. Figure 1). Then the heating system was turned on and the temperature started rising significantly while humidity started to decrease. After 2 hours of the journey the bus stopped for about half an hour. At that time, the temperature was constant while humidity was decreasing. 


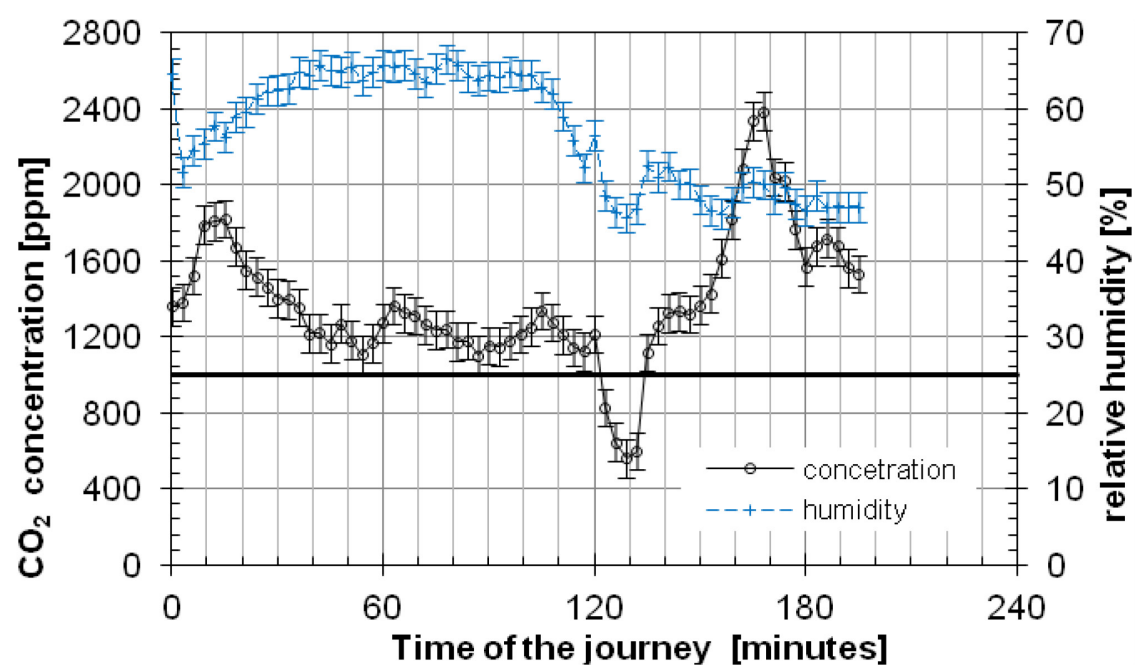

Figure 2: Relative humidity and carbon dioxide concentration in the bus during the outbound journey.

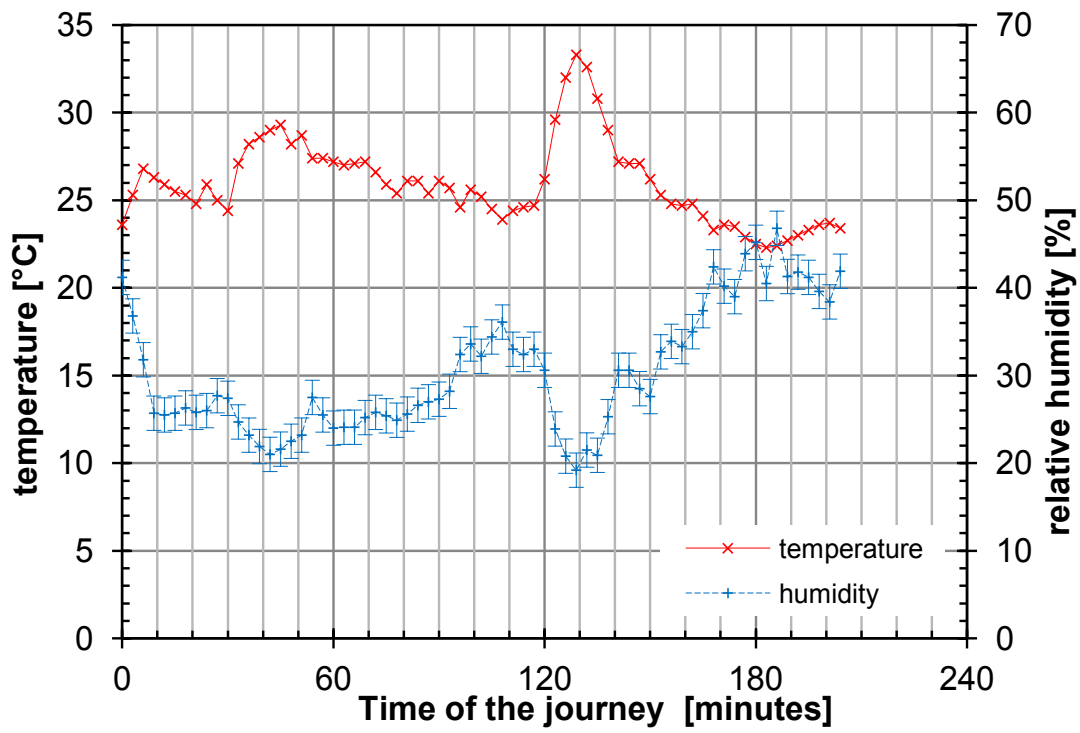

Figure 3: Temperature and relative humidity in the bus during the return journey.

When the bus started the temperature began to increase; humidity rose, initially; then it started to decrease. As the heating was turned off (in the $153^{\text {rd }}$ minute) temperature was almost constant while humidity oscillated at about $48 \%$.

Carbon dioxide concentration (later named as "concentration") increased during the first 15 minutes of the journey up to $1823 \mathrm{ppm}$. Then, it was dropping 
to about $1200 \mathrm{ppm}$ to the $40^{\text {th }}$ minute (see in Figure 2). The concentration was oscillating about $1200 \mathrm{ppm}$ from that time to the break in the journey. During the break the concentration dropped to $562 \mathrm{ppm}$. When the bus started the concentration started to rise up to $2340 \mathrm{ppm}$ and then it dropped to about 1600 ppm.

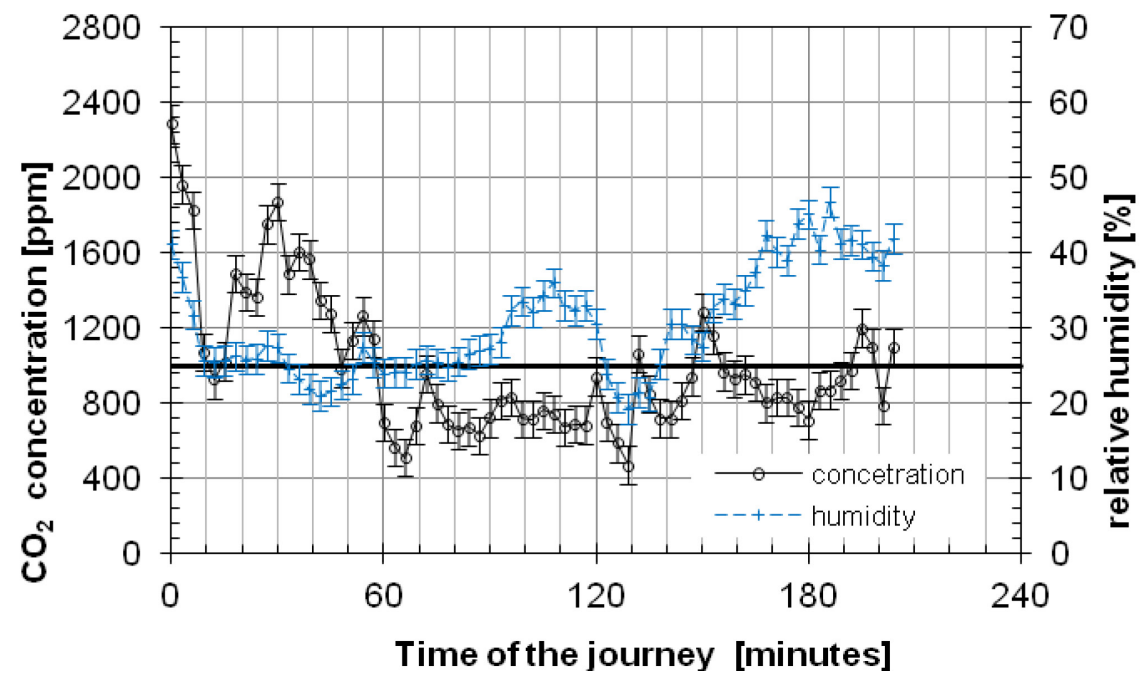

Figure 4: Relative humidity and carbon dioxide concentration in the bus during the return journey.

During the return journey the measuring instrument was placed in the back part of the bus. At that time, the air was warmer than before and humidity was strictly depending on temperature: when temperature was increasing humidity was decreasing or vice versa (cf. Figure 3). Relative humidity and the concentration were correlated up to the $156^{\text {th }}$ minute: both parameters increased or decreased with a short delay (see in Figure 4). Then we can observe negative correlation almost to the end of the journey.

\section{Calculations}

To do precise calculations the flow meters must be installed in all the openings in the bus; in the grilles and the windows. An installation of a flow meter in the window near the driver would fail the job security because it could distract the driver. For that reason measurements inside the bus were conducted only. We estimate the share of outdoor air as follows. The number of molecules is calculated under the assumption that the air is ideal gas. Then the amount of exhaled carbon dioxide is obtained. Eventually, the carbon dioxide is balanced in the bus and the share of outdoor air is calculated from the balance equation. 
The number of molecules in the bus is calculated using the ideal gas law. It equals to product of quantity of air moles' in the bus in measured conditions (the ratio in the formula) and Avogadro number:

$$
n_{\text {bus }}=\frac{V T_{0} p}{p_{0}(t+273.15) V_{\text {mol }}} N_{A} \quad[-]
$$

where:

$p$ - measured pressure in the bus, $[\mathrm{hPa}]$

$t$ - measured temperature in the bus, $\left[{ }^{\circ} \mathrm{C}\right]$

other constants are in Table 1.

Table 1: Data for calculations.

\begin{tabular}{|llc|}
\hline$C_{\text {co out }}$ & outdoor $\mathrm{CO}_{2}$ concentration & $385 \mathrm{ppm}$ \\
\hline$g_{\text {driver }}$ & $\mathrm{CO}_{2}$ gains from driver & $66 \mathrm{~g} / \mathrm{h}^{\mathrm{a})}$ \\
\hline$g_{\text {pass }}$ & $\mathrm{CO}_{2}$ gains from passenger & $35 \mathrm{~g} / \mathrm{h}^{\mathrm{a}}$ \\
\hline$n_{\text {pass }}$ & Number of passengers & 24 \\
\hline$\tau$ & Time between measurements & 3 minutes \\
\hline$N_{A}$ & Avogadro number & $6.02204500 \cdot 10^{23} \mathrm{~mol}^{-1}$ \\
\hline$\mu_{\mathrm{CO}_{2}}$ & Molar mass of $\mathrm{CO}_{2}$ & $44.00995 \mathrm{~g} / \mathrm{mol}^{-1}$ \\
\hline$V$ & Volume of the bus & $33,600 \mathrm{dm}^{3}$ \\
\hline$T_{0}$ & Temperature in normal conditions & $273.15 \mathrm{~K}$ \\
\hline$p_{0}$ & Pressure in normal conditions & $1013.25 \mathrm{hPa}$ \\
\hline$V_{\text {mol }}$ & $\begin{array}{l}\text { Volume of 1 mole gas in normal } \\
\text { conditions }\end{array}$ & $22.4 \mathrm{dm}^{3} / \mathrm{mol}$ \\
\hline
\end{tabular}

a) values taken from experiments conducted by Gładyszewska-Fiedoruk [1, pp. 327-331].

Production of carbon dioxide molecules is calculated as follows:

$$
\Delta n_{\mathrm{CO}_{2}}=\left(g_{\text {driver }}+n_{\text {pass }} g_{\text {pass }}\right) \tau N_{A} / \mu_{\mathrm{CO}_{2}} \quad[-]
$$

The definitions of the symbols, and data for calculations are shown in Table 1.

Carbon dioxide molecules' amount in the bus cabin in a calculated period is the sum of its amount in previous $\mathrm{CO}_{2}$ measurement, $\mathrm{CO}_{2}$ production, $\mathrm{CO}_{2}$ inflow from outside and its outflow. Because concentration is obtained from formula:

$$
C_{\mathrm{CO}_{2}}=\frac{n_{\mathrm{CO}_{2}}}{n_{\text {bus }}} 10^{6} \quad[\mathrm{ppm}]
$$

we obtain:

$$
C_{c 0_{2}}=C_{c 0_{2} \text { prev }}+\frac{\Delta n_{c 0_{2}} \cdot 10^{6}}{n_{b u s}}+C_{c 0_{2} \text { out }} s-\left(C_{c 0_{2} \text { prev }}+\frac{\Delta n_{c 0_{2}} \cdot 10^{6}}{n_{\text {bus }}}\right) s \quad[\mathrm{ppm}]
$$


754 Safety and Security Engineering V

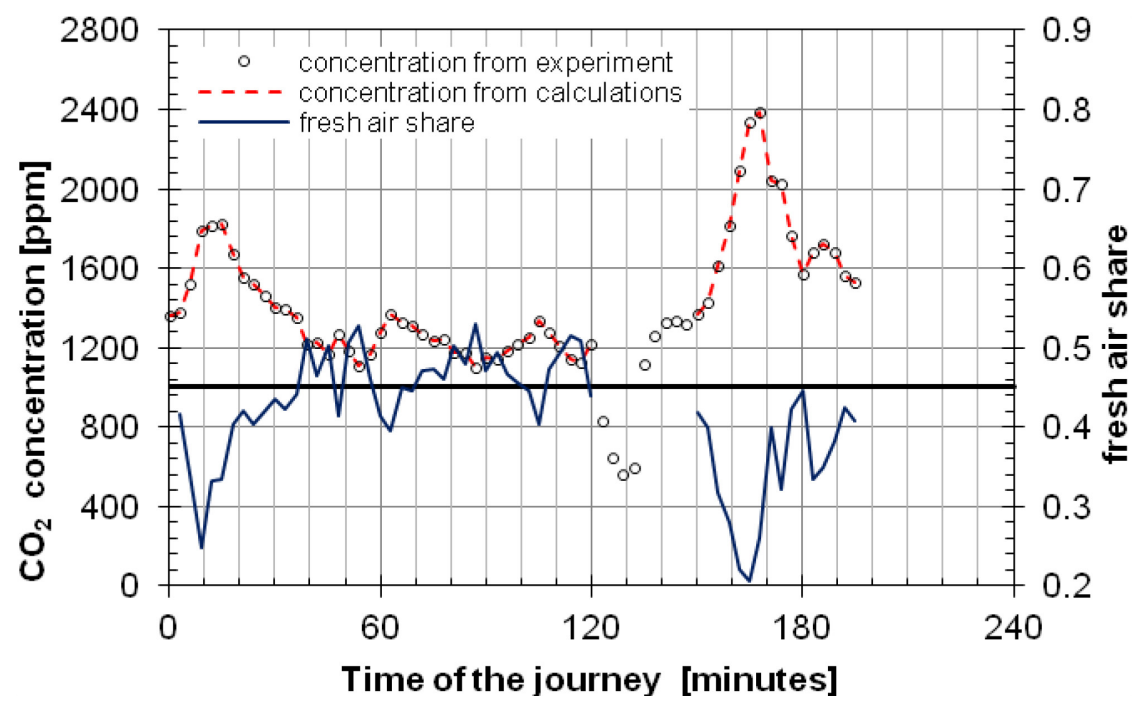

Figure 5: The replacing of air during the outbound journey.

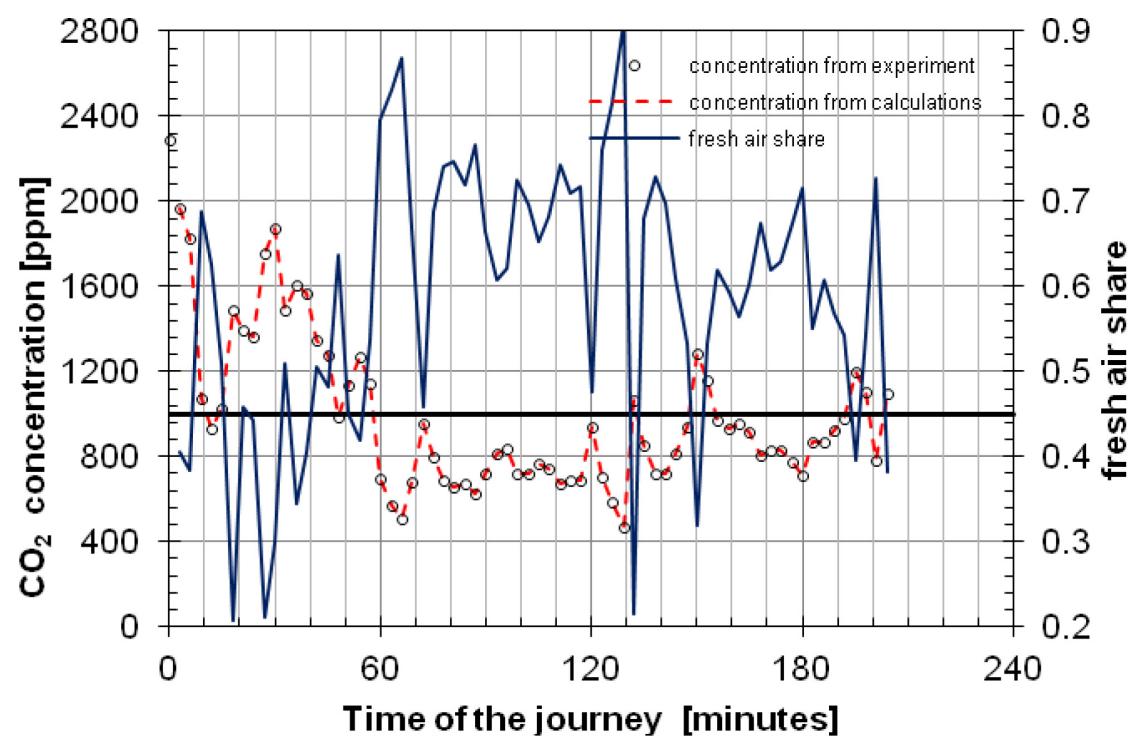

Figure 6: The replacing of air during the return journey.

After some transformations we obtain the share of fresh air in the bus:

$$
s=\frac{C_{c O_{2}}-C_{c O_{2} \text { prev }}-\Delta n_{c o_{2}} \cdot 10^{6} / n_{b u s}}{C_{c O_{2} \text { out }}-C_{c o_{2} \text { prev }}-\Delta n_{c o_{2}} \cdot 10^{6} / n_{b u s}} \quad[-]
$$


where:

$C_{\mathrm{co}_{2}}$ - actual $\mathrm{CO}_{2}$ concentration, [ppm]

$C_{\mathrm{Co}_{2} \text { prev }}$ - measured $\mathrm{CO}_{2}$ concentration a moment before, [ppm]

$\mathrm{C}_{\mathrm{Co}_{2} \text { out }}$ - outdoor $\mathrm{CO}_{2}$ concentration (cf. Table 1), [ppm]

The results of Eq. (5) are solid polylines plotted in Figures 5 and 6. The calculations in Figure 5 are interrupted during the stopover period. The lowest share of fresh air during the outbound journey was at 0.206 in the $162^{\text {nd }}$ minute and the biggest share was calculated at 0.529 in the $87^{\text {th }}$ minute. The average share during this journey was at 0.418 . Because of higher temperature during the return journey, the share of outside air increased. While the least and most share were at 0.207 in the $18^{\text {th }}$ minute and at 0.912 in the $129^{\text {th }}$ minute respectively. The average share of fresh air was 1.41 times greater than before and it was at 0.587 .

\section{Discussion}

Because, carbon dioxide and vapour are the products of human being metabolism they both should be correlated. Any observed delay (cf. Figure 4) was caused by an apparatus's lag. When air is warmed its relative humidity decreases, but when it is cooled its relative humidity increases up to the dew point, where relative humidity is equal to $1(100 \%)$ under constant specific humidity. Therefore, for a temperature higher than dew temperature and when specific humidity is constant we can say the temperature and relative humidity are negatively correlated.

During the outbound journey the air was recirculated in the majority because the relative humidity, temperature, and concentration increased simultaneously between the stopover and the $165^{\text {th }}$ minute of the journey (Figures 1 and 2). At this moment the maximum concentration was measured. Probably the driver felt uncomfortable and outside air share increased significantly. This hypothesis agrees with Gładyszewska-Fiedoruk [1, pp. 327-331] investigations.

During the return trip the temperature in the bus was higher than during the previous journey. Therefore, the share of outdoor air was greater. Moreover, we can observe the negative correlation of temperature and humidity. Although, humidity and concentration were correlated, the concentration step by step decreased and the maximum concentration was observed at the beginning of the return journey.

The maximum permitted indoor carbon dioxide concentration is $1000 \mathrm{ppm}$. This value is established by the European Branch of World Health Organization [3] and by ASHRAE [4]. This value is plotted in Figures 2, 4, 5, and 6 as the horizontal tick line. We can observe, in the case of the journey there these standards were satisfied only during the stopover (cf. Figure 2). In the case of the return journey permitted concentration was during the middle period of this trip (cf. Figure 4). 


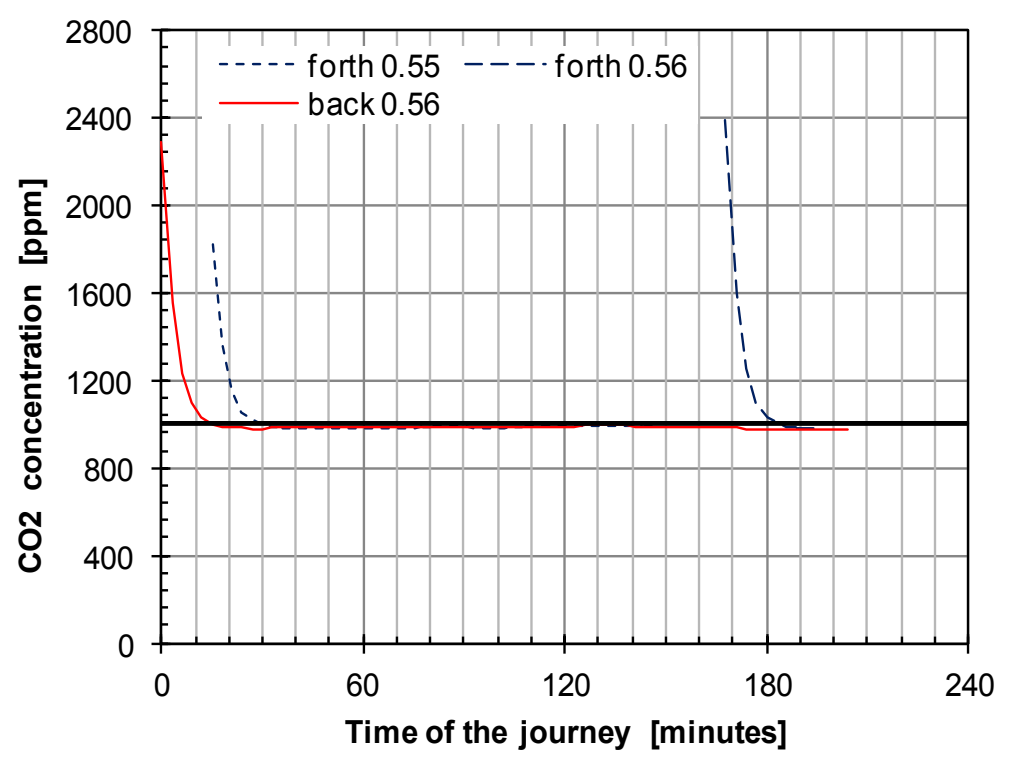

Figure 7: Simulation of internal $\mathrm{CO}_{2}$ concentration decreasing.

To maintain the above mentioned standards a minimal amount of fresh air should be supplied. Therefore, the minimal share of outdoor air is calculated. Then the share is used in Eq. (4), other variables and constants are taken from experiment or earlier calculations and the results are plotted in Figure 7. As the measured concentration a moment before were taken the maximal measured concentration values: two during the journey there and one during the one back. In the first case (at the beginning of the journey there) the standard concentration value would be achieved after 15 minutes if the share of fresh air was at 0.55 . In the next cases the share should be at least 0.56 and time needed to fail the concentration below allowed value would be 18 minutes.

If the temperature and pressure in the bus were constant, the amount of molecules in the cabin would be constant too. Therefore, after the initial period the concentration should be constant. Because the air parameters changed the calculated concentration varied slightly.

It is said, the most dangerous periods in the journeys are the first and last $23 \mathrm{~km}$. This distance corresponds to about 30 minutes of the ride in the investigated cases. In Figure 2 we observe two maximal values of concentration in the both mentioned periods. In Figure 4 the most dangerous situation is observed at the beginning of the return journey, when the concentration was the highest.

\section{Acknowledgement}

This work was funded by Bialystok University of Technology as the Dean's project S/WBiIŚ/5/2011. 


\section{References}

[1] Gładyszewska-Fiedoruk, K., Concentrations of carbon dioxide in a car, Transportation Research Part D 2011, 16.

[2] PN-EN 13779, 2008. Ventilation of Residential Buildings. Requirements for the Properties of Ventilation and air Conditioning.

[3] World Health Organization (WHO), 2000. Air Quality Guidelines for Europe, second ed. European Series, No. 91 WHO Regional Office for Europe Copenhagen, Geneva.

[4] ASHRAE, 1989. Standard 62-1989. Ventilation for Acceptable Indoor Air Quality. ASHRAE, Atlanta. 